\title{
The SAPhTE Study: The comparison of the SAPhTE (Safe-T) workload measurement tool against the current in-service tool within Queensland Health's Emergency Medicine Departments ${ }^{\text {is }}$
}

\author{
John Degan, RN, BN, Grad Cert Emergency Care*, Paul Negus, RN, BN
}

Department of Emergency Medicine, Nambour General Hospital, PO Box 547, Nambour, Qld 4560, Australia

Received 22 July 2008; received in revised form 22 October 2008; accepted 23 November 2008

\section{KEYWORDS \\ SAPhTE; \\ Emergency; \\ Workload; \\ $\mathrm{ECHO}$}

\begin{abstract}
Summary
Background: Emergency Departments need management tools that keep up with the changing demands of the emergency work environment. There is a need for a tool that accurately measures overall Emergency Department demand in real time that can provide predictive ED information and be linked to local escalation strategies.

Method: To test the validity of the SAPhTE scoring matrix as a tool to measure Emergency Department pressures in real time. To achieve this, the relationship between the SAPhTE matrix and other Emergency Department performance indicators were explored.

Results: The SAPhTE score had a high correlation to the ECHO score, however both scores had a poor correlation to the daily mean number of presentations/admissions.

Conclusion: The SAPhTE score is a viable tool for use in the Emergency Department setting, and has the advantage over ECHO in that staffing and environmental factors are reflected within the scoring system.

(c) 2008 College of Emergency Nursing Australasia Ltd. Published by Elsevier Ltd. All rights reserved.
\end{abstract}

\footnotetext{
J Degan contributed to the development of the study protocol. P Negus performed the statistical analysis collection. All authors contributed to the preparation of the final manuscript.

* Corresponding author. Tel.: +61 75470 6590; fax: +61 754706795.

E-mail addresses: Jdjen06@hotmail.com (J. Degan), Paul_negus@health.qld.gov.au (P. Negus).
}

1574-6267/\$ - see front matter @ 2008 College of Emergency Nursing Australasia Ltd. Published by Elsevier Ltd. All rights reserved. doi:10.1016/j.aenj.2008.11.005 


\section{Introduction}

Despite the volatile and dynamic environment of emergency work, staffs of busy Emergency Departments (ED) instinctively know when a day, week or month has been good or bad. Yet it is not until performance data has been collected, analysed and disseminated that senior decision makers can perceive the extent of demands placed on ED resources. A broad range of issues are faced by staff in the emergency environment, yet the pivotal issue still seems to be that of an over-demand for ED resources. ${ }^{1}$ ED crowding is recognised as a major international problem concern that affects patients and providers. ${ }^{2-4}$ Recent research that examined over-demand of ED services has mentioned the value of predicting the near future status of the ED, which would allow the trigger of early interventions designed to reduce the burden of over-demand before a situation crisis arises. ${ }^{3,5-7}$ With support of this and other research it has been identified that a gap in real-time ED information has the potential to hinder the ability to effectively deal with the problems associated with over-demand as they develop.

To solve this problem, development of an ED workload tool that could provide timely and accurate information and identify ED workload issues before they become compounded and unmanageable was proposed. ${ }^{8}$ An ED management tool (SAPhTE) was sourced, upgraded for electronic use, and implemented within Nambour ED, Sunshine Coast and Cooloola Health Service District (SCCHSD), Queensland, Australia. This tool had been originally made available by the National Institute of Clinical Studies who assisted with work in Darwin. It is currently being used at a number of ED's in South-East Queensland as a way of identifying increasing ED workload. This study builds on the work done in the Wales National Health System (NHS) that used this tool as a form of ED reporting. ${ }^{9}$ A comprehensive literature search showed that no published study has been conducted using this tool.

The SAPhTE tool is a matrix with sets of criteria arranged under five key aspects of the ED that have the greatest potential to effect optimum ED functioning (Fig. 1). The matrix quantifies staffing levels $(S)$, acuity of patients to be seen $(A)$, the physical capacity of the ED $(\mathrm{Ph})$, transfers of inpatients to wards $(T)$, and the working environment $(E)$. A score of $1-5$ is then assigned to each section giving a total score between 5 and 25. Lower scores indicate optimum ED functioning. Higher scores indicate increasing levels of workload stressors.

This tool is referred to as the SAPhTE matrix and broadly represents factors affecting ED functioning. The matrix can be accurately and rapidly completed. The overall goal of implementing the SAPhTE matrix was to create a safe and manageable ED. This study aimed to validate the SAPhTE matrix against the current Emergency Capacity Hospital Overview (ECHO) application ${ }^{10}$ (Fig. 2), and against daily mean admissions and presentations. Identifying variables that can influence ED decision making may help streamline the proportionality of resources used to deal with demand issues. This may have a financial benefit by appropriately allocating resources as the need arises.

\section{Method}

With institutional approvals, this study was conducted in the ED of Nambour Hospital from 14th December 2007 through to the 1st March 2008. Nambour Hospital is a level three facility seeing close to 35,000 presentations each year. The SAPhTE scoring matrix was proposed to be used to assist decision makers at all levels to respond to changing ED pressures. The

\begin{tabular}{|c|c|c|c|c|c|}
\hline Score & Staffing & Acuity & Physical Capacity & Disposition/Transfer & Environment \\
\hline 5 & $\begin{array}{l}\square * \text { Resuscitation/Trauma area } \\
\text { requiring more than } 4 \text { nurses or } 3 \\
\text { doctors. }\end{array}$ & $\begin{array}{l}\square * \text { Unable to see NTS } 1 \text { patients } \\
\text { in a team approach immediately on } \\
\text { arrival. }\end{array}$ & $\begin{array}{l}\square * \text { All Resuscitation bays } \\
\text { full with no alternative space } \\
\text { available. }\end{array}$ & $\begin{array}{l}\square * \text { More than } 11 \\
\text { patients awaiting ward } \\
\text { allocation. }\end{array}$ & $\begin{array}{l}\square * \text { Any designated resuscitation or } \\
\text { trauma patient managed in a corridor. }\end{array}$ \\
\hline 4 & $\begin{array}{l}\square * 1: 1 \text { patient ratio in all } \\
\text { resuscitation bays. }\end{array}$ & $\begin{array}{l}\square^{*} \text { Any NTS } 2 \text { patients with } \\
\text { time to treatment more than } 10 \\
\text { minutes. }\end{array}$ & $\begin{array}{l}\square * \text { All Acute beds full with } \\
\text { patients in corridors. }\end{array}$ & $\begin{array}{l}\square * 8-10 \text { patients } \\
\text { waiting for an inpatient } \\
\text { bed. } \\
\square^{\text {or }} 2 \text { or more patients } \\
\text { awaiting ICU, CCU or } \\
\text { HDU bed. }\end{array}$ & $\begin{array}{l}\square \text { Any patient not receiving basic } \\
\text { needs in a timely manner eg food, } \\
\text { drink, elimination, ordered } \\
\text { medication. }\end{array}$ \\
\hline 3 & $\begin{array}{l}\square^{*}>\text { allocated nurse to patient ratio in } \\
\text { acute. } \\
\square^{\text {or }} \text { Team out of department. } \\
\square^{\text {or }} \text { Clinical staff unable to take } \\
\text { breaks. }\end{array}$ & $\begin{array}{l}\square * \text { More than } 3 \text { NTS } 3 \text { patients } \\
\text { with time to treatment more than } \\
30 \text { minutes. } \\
\square^{\text {or }} \text { Any NTS } 3 \text { patient with time } \\
\text { to treatment more than } 60 \text { minutes. } \\
\square^{\text {or }} \text { More than } 10 \text { NTS } 4 \text { patients } \\
\text { with time to treatment more than } \\
60 \text { minutes. }\end{array}$ & $\begin{array}{l}\square * 2 \text { or less bed spaces in } \\
\text { DEM. }\end{array}$ & $\begin{array}{l}\square^{*} 6-7 \text { patients waiting } \\
\text { for an inpatient bed. } \\
\square^{\text {or }} \text { Any patient in } \\
\text { department awaiting } \\
\text { disposition or transfer for } \\
\text { more than } 8 \text { hours. }\end{array}$ & $\begin{array}{l}\square \text { Any security alert within a patient } \\
\text { care area ie. Any patient regulated } \\
\text { under the mental health act who is } \\
\text { unmonitored. }\end{array}$ \\
\hline 2 & $\begin{array}{l}\square^{*} \text { More than } 1 \text { Nursing/Medical } \\
\text { staff member down } \\
\square^{\text {or }} \text { More than } 1 \text { Nursing/Medical } \\
\text { staff member on overtime/call in. }\end{array}$ & $\begin{array}{l}\square * \text { More than } 5 \text { NTS } 4 \text { patients } \\
\text { with time to treatment over } 60 \\
\text { minutes. }\end{array}$ & $\begin{array}{l}\square * \text { Less than } 4 \text { bed spaces in } \\
\text { DEM. }\end{array}$ & $\begin{array}{l}\square * 3-5 \text { patients waiting } \\
\text { for an inpatient bed. }\end{array}$ & $\begin{array}{l}\square * \text { Any loss of dignity and } \\
\text { confidentiality for a patient without } \\
\text { compromise of clinical safety. }\end{array}$ \\
\hline 1 & $\begin{array}{l}\square * \text { Able to assess, monitor, perform } \\
\text { observations and commence treatment } \\
\text { on all patients as per standing orders. }\end{array}$ & $\begin{array}{l}\square * \text { All NTS } 1-5 \text { patients being } \\
\text { seen within normal national } \\
\text { guideline target times. }\end{array}$ & $\begin{array}{l}\square * \text { Immediate capacity to } \\
\text { deal with resuscitation cases } \\
\text { and capacity to see new cases. }\end{array}$ & $\begin{array}{l}\square^{*}<3 \text { patients waiting } \\
\text { for an inpatient bed. }\end{array}$ & $\begin{array}{l}\square * \text { All patients treated with dignity } \\
\text { and confidentiality in an appropriate } \\
\text { area. }\end{array}$ \\
\hline
\end{tabular}

Figure 1 Example of SAPhTE matrix used in the study. 


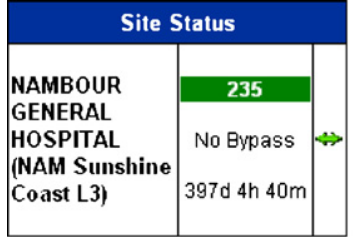

\begin{tabular}{|l|l|}
\hline \multicolumn{2}{|c|}{ Patient Data } \\
\hline Average Wait Time & $0 \mathrm{~h} \mathrm{34m}$ \\
\hline Average Triage Wait & Oh 3m \\
\hline Access Block & 12 \\
\hline Daily Average & 91.18 \\
\hline Total Today & 20 \\
\hline Discharged & 24 \\
\hline
\end{tabular}

\begin{tabular}{|l|l|l|}
\hline \multicolumn{3}{|c|}{ Bed Utilisation } \\
\hline Resus & $0 / 3$ & $0 \%$ \\
\hline Acute & $12 / 13$ & $\mathbf{9 2} \%$ \\
\hline Sub-Acute & $0 / 0$ & $0 \%$ \\
\hline Observation & $7 / 10$ & $70 \%$ \\
\hline Other & $1 / 6$ & $17 \%$ \\
\hline Fractional Capacity & & $77 \%$ \\
\hline
\end{tabular}

\begin{tabular}{|l|l|}
\hline \multicolumn{2}{|c|}{ Bed Status } \\
\hline Good & \\
Time on Current Status: & \\
397d 4h 40m & \\
Last Updated: & \\
\hline $397 d$ h 40m & 2 \\
\hline Manual Bed Count & 0 \\
\hline HBClS Bed Count & \\
\hline
\end{tabular}

Figure 2 An example of the ECHO tool.

nurse coordinator of each shift was responsible for completing the electronic SAPhTE matrix due to the fact that they have a global understanding of the ED function at all times. For the study purpose the SAPhTE matrix was completed at set times $(00: 00,04: 00,08: 00,12: 00,16: 00$ and 20:00) and at times of high acuity. Building on from previous work done in relation to the SAPhTE matrix, ${ }^{9}$ it was important for this study period that there were actions linked to the generated SAPhTE score.

Nambour Hospital has a capacity alert action plan which consists of strategies to ensure safe patient care, a safe work environment and workload for all staff. ${ }^{11}$ The SAPhTE score was linked to these local capacity action plans for the duration of this study. This builds a relationship between hospital performance and the SAPhTE based management tool. A score of 5-10 was indicative of optimum emergency functioning and is considered an acceptable risk to patient care. A score of 11-15 highlights the potential risk to patient care and allows the nurse coordinator to consider activating the hospital pre-capacity alert. A score of 16-20 highlights an unacceptable risk to patient care. The nurse coordinator will consider activating the capacity alert system as the maximum pressure valve has been exceeded and ED efficiency has deteriorated. A score of 21-25 highlights a critical risk to patient care. Here there is a fundamental demand/supply mismatch which can result in the ED and hospital being compromised. The nurse coordinator at this stage should consider activating the extreme capacity alert.
The trigger for activation of each capacity alert is discretionary and at times done in consultation with the medical clinical coordinator. The SAPhTE score gives added weight and consistency to the activation of each capacity alert action plan. This supports the purpose of Nambour General Hospital's capacity action plans which should respond effectively to early indications of increasing demand for service in order to provide timely, safe access to appropriate care to all patients. ${ }^{11}$

Before implementing the SAPhTE matrix trial, nursing and medical staff received education ensuring understanding of the tool and study objectives. For the trial period, the electronic SAPhTE matrix was set up as a stand alone web page with no linkage to a Queensland Health server. Once a SAPhTE score was generated the staff were instructed to print the generated screen and place in an allocated collection box which allowed for future validation and data analysis. The collected data was entered into a Microsoft excel spreadsheet (Fig. 3). This data was then transferred into a statistical program (SPSS) for further statistical analysis.

During the data analysis individual SAPhTE scores were correlated against daily presentations and admissions, and against an ECHO score. The ECHO score used was time and date matched to the SAPhTE score generated. A secondary analysis of the correlation of daily average SAPhTE and ECHO scores against daily admissions and presentations was also performed.

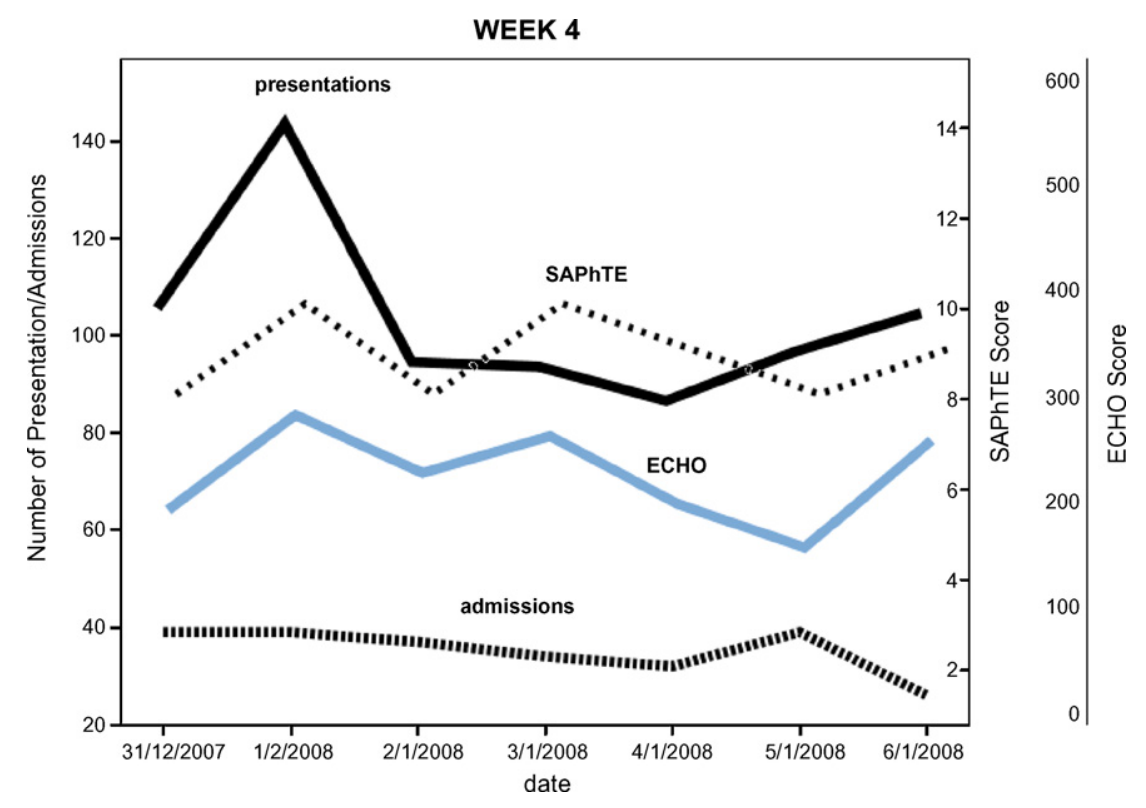

Figure 3 An example of the daily average SAPhTE score, ECHO score, presentations and admissions over a 1 week period. 


\begin{tabular}{|lll|r|r|}
\hline & & SAPhTE & \multicolumn{1}{|c|}{ ECHO } \\
\hline Spearman's rho & SAPhTE & Correlation Coefficient & 1.000 & $.670\left(^{* *}\right)$ \\
& & Sig. (2-tailed) &. & .000 \\
& & $\mathrm{~N}$ & 322 & 322 \\
& \multirow{2}{*}{ ECHO } & Correlation Coefficient & $.670\left({ }^{* *}\right)$ & 1.000 \\
& & .000 & \\
& & Sig. (2-tailed) & 322 & 322 \\
\hline
\end{tabular}

** Correlation is significant at the 0.01 level (2-tailed).

Figure 4 SAPhTE vs. ECHO Spearman's rank correlation.

\section{Results}

ED presentations and admissions were used in comparison to the SAPhTE score, as they are two common indicators used to gauge ED functioning and pressures. These indicators do not represent performance of an ED, but do represent core activities.

To validate the SAPhTE matrix, correlations were tested using Spearman's rank correlation coefficient against daily admissions, presentations, and against a current ECHO score which was time matched against each SAPhTE score generated. The Spearman's rank correlation indicates either a weak $(0.0-0.5)$, moderate $(0.51-0.8)$ or strong/high (0.81-1.0) correlation. Upon testing, ECHO and SAPHTE had a moderate positive correlation with a Spearman-correlation of 0.670 , with a significance level of 0.01 (Fig. 4).

Upon correlating SAPhTE and Echo scores against daily presentations and admissions, a poor correlation was identified, this is an expected result as presentation and admissions totals are a total daily aggregate score, compared to SAPhTE/ECHO which are a snapshot of real time data.

When comparing the daily average SAPhTE and time matched ECHO scores against daily presentations and admissions, again poor correlations were exhibited, with all correlations $<0.2$. This again reinforces that both SAPHTE and ECHO scores have utility in reflecting ED workload at individual time points, however these individual scores are not a reflection of ED workload over a 24 hour period.

Summarizing these results, the SAPhTE and ECHO scores as emergency department workload tools demonstrate a moderate correlation to each other in calculating workplace function, with both scores providing a snapshot of an ED's workload at set time points within a 24 hour period. As each score only reflects workload activity at individual time points they have a poor correlation with an ED's daily presentations and admissions.

\section{Discussion}

The challenge for any ED now and in the future is to accommodate variations in demand beyond normal operational capacity. The SAPhTE matrix will allow for consistency in using and standing down local configurable escalation strategies that deal with over demand. This will allow for the consistent application and allocation of resources at times of high demand and there reduction when no longer required. The SAPhTE matrix will hopefully allow departments to strike a balance between human and financial costs involved in dealing with over-demand in the ED.
The SAPhTE score captures a moment in time that reflects the interaction between two elements-workload vs. resources and patient flow vs. outflow. It provides a strong indicator of when the ED's ability to cope has been exceeded and therefore can reliably be used as a trigger for the consistent use of local escalation strategies. This aims to prevent problems compounding.

Limitations of ECHO should also be explored. It would be very difficult to link an ECHO score to local escalation strategies due to the $15 \mathrm{~min}$ delay that prevents capture of real time data, and also due to the fact that the ECHO score relies on EDIS data integrity inputted from a number of health care workers. ECHO, unlike the SAPhTE matrix, does not rapidly and clearly identify the area of greatest weakness to ED functioning. The SAPhTE matrix identifies and allows problem-solving strategies to be directed to this area of identified weakness. The SAPhTE generated score is from real-time data using an uncomplicated formula whereas the $\mathrm{ECHO}$ score uses a formula of calculating a work score that is generated by a large number of variables within a closed and automated system.

The results of this study have shown a moderate Spearman's rank correlation between SAPhTE and ECHO (0.670). The principal factor that prevented the two from achieving a higher correlation was due to the ECHO's inability to capture local staffing and environmental concerns. For example, on one occasion, the SAPhTE matrix highlighted staffing concerns, with the resuscitation area needing more than 4 nurses and 3 doctors (close to $50 \%$ of shift staffing). At the same time the matrix identified environmental concerns that patients were not receiving basics needs (medications, elimination etc) in a timely manner. The generated SAPhTE score was 21 , correctly indicating a critical risk to patient care compared to the generated ECHO score of 203, falsely indicating that the workload status was low. ${ }^{10}$ The ECHO score was not an accurate reflection of ED status at this specified time point.

$\mathrm{ECHO}$ as a business intelligence tool has a high level of utility in assessing multiple ED's performance at a strategic level, but because of it's inability to capture local ED resource usage and environmental factors, it has limited utility in providing a decision pathway in implementing precapacity and capacity alerts. The SAPhTE matrix, whilst providing a decision making pathway that has a moderate correlation with the statewide ECHO tool, has the additional sensitivity to detect local factors that can impact on an ED's performance. Due to it's ease of use in calculating real time workload status, it provides a high level of utility in allowing a shift coordinator to accurately identify when to implement and remove local capacity alerts.

\section{Recommendation}

It is important that EDs gain confidence in using such a tool as the SAPhTE matrix before asking other sections of the hospital to accept it. The main recommendation is for the electronic SAPhTE matrix to be updated and incorporated with ECHO. This would allow for a more efficient management and identification of ED problems that can be investigated and actioned by senior management, both medical and nursing. This would also help facilitate a district 
approach for managing demand on EDs. Other articles examining ED pressures supports this idea of sharing information about ED operating status between neighbouring institutions as a major step of addressing ED pressures. ${ }^{3,7}$

ECHO and SAPhTE can both play roles in managing ED demand. The main role of SAPhTE should be for the trigger of local escalation strategies with $\mathrm{ECHO}$ providing another set of performance data that can be analysed retrospectively by management and executive teams.

\section{Conclusion}

The SAPhTE matrix can play a role in managing and describing ED pressures. It can act as a reliable trigger for further investigation and action of ED performance. This research contributes to the clinical validity and reliability of using ED management tools that incorporate human and environmental factors. It is hoped that this research will improve ED practice of managing demand and supply. It is hoped this review will aid in dissemination of other research findings looking at other emergency workload management tools that help ED performance.

\section{Conflict of Interest}

None declared.

\section{Funding of Financial Interests}

None declared.

\section{References}

1. Heyworth J. Stress: a badge of honour in the emergency department. Emerg Med Australas 2004;16:5-6.

2. Levin S, Aronsky D, Hemphill R, Han J, Slagle J, France D. Shifting toward balance: measuring the distribution of workload among emergency physician teams. Ann Emerg Med 2007; 4:419-23.

3. Hoot N, LeBlanc L, Jones I, Levin S, Zhou C, Gadd C, et al. Forcasting emergency department crowding: a discrete event simulation. Ann Emerg Med 2008;52(2):116-25.

4. Hoot N, Zhou C, Jones I, Aronsky D. Measuring and forecasting emergency department crowding in real time. Ann Emerg Med 2007;6:747-55.

5. Kelen G, Scheulen J, Hill P. Effect of an emergency department managed acute care unit on ED overcrowding and emergency medical services diversion. Acad Emerg Med 2001;8:1095-100.

6. Forster A. An agenda for reducing emergency department crowding. Ann Emerg Med 2005;45:479-81.

7. Sprivulis P, Gerrard B. Internet-accessible emergency department workload information reduces ambulance diversion. Prehosp Emerg Care 2005;9:285-91.

8. Epstein S, Tian L. Development of an emergency department work score to predict ambulance diversion. Acad Emerg Med 2006;13(4):459-61.

9. NHS-Wales. Emergency pressures reporting systems. 2000. Available at: http://www.wales.nhs.uk/sites/documents/ 296/4.5\%20Reporting\%20Systems.pdf [accessed on 22 July 2008].

10. QueenslandHealth. ECHO user training maual. Brisbane; 2007. p. $1-27$.

11. Johnson D, Priestly S. Capacity alert action plan-Nambour Hospital. Nambour Hospital; 2007. 